\title{
Competências e habilidades desenvolvidas no ensino clínico prático em saúde do adulto e idoso: relato de experiência docente
}

Competences and skills developed in practical clinical teaching of adult and elderly health: teaching experience report

Competencias y habilidades desarrolladas em la enseñanza clínica práctica em salud del adulto y anciano: informe una experiencia docente

Caroline do Nascimento Leite ${ }^{1 *}$, Tânia Catarina Sobral Soares ${ }^{1}$, Rogério Jorge Cirillo Menezes Júnior $^{1}$, Daniela Vogel de Souza ${ }^{1}$, Marilene Lopes de Jesus ${ }^{1}$.

\section{RESUMO}

Objetivo: Refletir sobre a experiência dos docentes de enfermagem ao ministrarem a disciplina de ensino clínico prático em saúde do adulto idoso na graduação. Relato de experiência: Relato de experiência docente sobre as atividades práticas desenvolvidas na disciplina de ensino clínico prático em saúde do adulto idoso no $5^{\circ}$ período do curso de graduação em enfermagem de uma instituição de ensino superior localizada na região metropolitana do estado do Rio de Janeiro. Considerações finais: O desenvolvimento de competências e habilidades na graduação está diretamenteassociado aoalinhamento dos conhecimentos teóricos e práticossendo de vital importância para o processo de formação discente. A utilização de metodologias ativas, como a problematização, é uma ferramenta efetiva e facilitadora desse processo. Essa forma de gerenciar a disciplina fornece ao docente os instrumentos de avaliação necessários e fomenta a percepção deque o discente precisa ser estimulado a cada prática no intuito de despertar sua capacidade de desenvolver a avaliação do estado geral, emocionale psicossocial do seu cliente, tomadas de decisão e gerenciamento do cuidado permitindo assim o incremento da sistematização da assistência de enfermagem.

Palavras-Chave: Educação em Enfermagem, Ensino, Metodologias ativas.

\begin{abstract}
Objective: To reflect on the experience of nursing professors in teaching the subject ofPractical Clinical Teaching of Adult and Elderly Health in undergraduate courses. Experience report: Teaching experience report about the practical activities developed in the subject ofPractical Clinical Teaching of Adult and Elderly Health in the 5th period of the undergraduatenursing course at a higher education institution located in the Metropolitan Region of Rio deJaneiro State. Final considerations: The development of competences and skills in undergraduatecourses is directly associated with the alignment of theoretical and practical knowledge and is ofvital importance to the student training process. The use of active methodologies such asproblematization is an effective and facilitating tool for this process. This way of subjectmanagement provides the professor with the necessary assessment tools and fosters theperception that students need to be encouraged in each practice to arouse and develop theirability to assess their client's general, emotional and psychosocial state, their decision makingand care management, thus allowing the improvement of nursing care systematization.
\end{abstract}

Keywords: Nursing education, Teaching, Active methodologies.

1Universidade Estácio de Sá (UNESA) - Campus R9 Taquara. Rio de Janeiro (RJ).

*E-mail: carolnascimento0402@gmail.com

SUBMETIDO EM: 7/2019

ACEITO EM: $8 / 2019$

PUBLICADO EM: 9/2019

REAS/EJCH | Vol.Sup.29 | e1341 | DOI: https://doi.org/10.25248/reas.e1341.2019 Página 1 de $\mathbf{6}$ 


\section{RESUMEN}

Objetivo: Reflexionar sobre la experiencia de los profesores de enfermería al enseñar laasignatura de enseñanza clínica práctica en salud del adulto y anciano en el pregrado. Informe de experiencia: Informe de experiencia docente sobre las actividades prácticas desarrolladasen la asignatura de enseñanza clínica práctica en salud del adulto y anciano en el quintoperíodo del curso de pregrado en enfermería de una institución de educación superior ubicadaen la región metropolitana del estado de Rio de Janeiro. Consideraciones finales: El desarrollo decompetencias y habilidades en el pregrado está directamente asociado con la armonización delos conocimientos teóricos y prácticos y es de vital importancia para el proceso de formación delos estudiantes. El uso de metodologías activas como la problematización es una herramientaefectiva y facilitadora para este proceso. Esta forma de administrar la asignatura le provee alprofesor las herramientas de evaluación necesarias y fomenta la percepción de que elestudiante debe ser estimulado en cada práctica para despertar y desarrolar su capacidad deevaluación del estado general, emocional y psicosocial de sus clientes, su toma de decisionesy gestión del cuidado, permitiendo así la mejora de la sistematización de los cuidados deenfermería.

Palabras clave: Educación en enfermería, Enseñanza, Metodologías activas.

\section{INTRODUÇÃO}

O Projeto Pedagógico de Curso da Universidade Estácio de Sá (UNESA) preconiza que seus cursos oportunizem aos estudantes uma sólida formação, coma capacidade de análise e articulação de conceitos e argumentos, de interpretação e valorização dos fenômenos sociais e ambientais, aliadas a uma postura reflexiva e visão crítica que fomente a capacidade de trabalho em equipe, favoreça a aptidão para a aprendizagem autônoma e dinâmica, além da qualificação para a vida, o trabalho e o desenvolvimento da cidadania. As atividades preconizadas no Curso de Enfermagem têm como foco principal favorecer aos seus discentes uma formação integral, que alie fundamentação teórica e atuação prática, ambas indispensáveis ao exercício profissional, de forma atender as necessidades da sociedade e que possibilite o contato com o conhecimento global do segmento que irá atuar (PROJETO PEDAGÓGICO DE CURSO,2019).

As atividades práticas no ensino são alicerçadas no princípio da interdisciplinaridade, que irá permitir o estudo do ser social, interativo, autônomo e protagonista, baseado na fundamentação das diversas ciências com os quais possui ligação, o que possibilitará o desenvolvimento das competências, habilidades e saberes necessários à prática profissional (FERREIRA NRS, et al., 2016).

De acordo com as Diretrizes Curriculares para os cursos da área de saúde, todos os cursos definidos na Resolução MS/CNS 287 deverão ter o ensino direcionado ao desenvolvimento de competências e habilidades direcionadas ao profissional da saúde, bem como um projeto pedagógico permeado pelo perfil profissional e competências e habilidades esperadas, originando os conteúdos curriculares necessários à prática profissional. Assim, na busca pela transformação das práticas de saúde constata-se de que a formação de profissionais da área tem sido um dos obstáculos à inovação. E em decorrência desse aspecto, emerge, na área da saúde, um intenso debate, particularmente nas carreiras de Medicina e de Enfermagem, a respeito da necessidade de transformar a formação dos profissionais e as práticas de saúde (HUMEREZ DC e JANKEVICIUS JV, 2015).

Em uma perspectiva histórica, a formação profissional em saúde foi diretamente influenciada pela utilização de metodologias de cunho fortemente assistencial, focando no desenvolvimento de abordagens conservadoras, repartidas e complexas, nas quais se privilegiam apenas o saber curativista em detrimento das práticas voltadas à proteção e promoção da saúde (GONZÁLEZ-CHORDÁ VM e MACIÁ-SOLER ML, 2015).

Dessa forma, surgem as novas tendências pedagógicas, sendo uma delas a metodologia ativa, que reúne diversos métodos estratégicos no intuito de tornar o discente protagonista do desenvolvimento de sua formação, e o docenteum facilitador do processo ensino-aprendizagem (ROSARS, et al.2017). 
Diante do exposto, o presente estudo fundamenta-se em realizar, através de um relato de experiência, uma reflexão acerca das atividades práticas desenvolvidas na disciplina de ensino clínico prático de adulto e idoso da graduação em enfermagem da UNESA localizada no Campus Taquara R9 no Estado do Rio de Janeiro.

\section{RELATO DA EXPERIÊNCIA}

Relato de experiência de característico reflexivo baseado na vivência dos docentes ao ministrar a disciplina de ensino clínico prático em adulto e idoso para discentes do $5^{\text {a }}$ período da graduação em enfermagem na UNESA Campus Taquara R9.

Para melhor descrever a experiência, cabe aqui esclarecer que as disciplinas de ensino clínico prático da instituição visam proporcionar aos discentes as seguintes competências e habilidades: Incorporação da ciência/arte do cuidar como instrumento de interpretação profissional; desenvolvimento da formação técnicocientífica que confira qualidade ao exercício profissional; reconhecimento da saúde como direito e condições dignas de vida e atuação de forma a garantir a integralidade da assistência, entendida como uma conjunção de elementos articulada e contínua, com vistas às ações e serviços preventivos e curativos, individuais e coletivos, requeridos individualmente em cada nível de complexidade do sistema; atuação nos programas de assistência integral à saúde da criança, do adolescente, da mulher, do adulto e do idoso; atuação nos diferentes cenários da prática profissional, considerando os pressupostos dos modelos clínico e epidemiológico; intervenção no processo de saúde-doença, qualidade da assistência/cuidado de enfermagem em seus diferentes níveis de atenção à saúde, com ações de promoção, prevenção, proteção e reabilitação à saúde, na perspectiva da integralidade da assistência e atuação profissional compreendendo a natureza humana em suas dimensões, em suas expressões e fases evolutivas.

A vivência dos docentes ocorreu durante um período de 6 meses, entre fevereiro e julho de 2019. As disciplinas de ensino clínico da instituição são constituídas pela parteteórica e prática. A parte prática é cumprida através da divisão das atividades, mediante cronograma, da seguinte forma: $1 / 3$ de aulas práticas em laboratório, 1/3 de visitas técnicas supervisionadas e 1/3 das atividades no consultório de enfermagem disponível no próprio campus. Durante as aulas de laboratório os discentes têm a oportunidade de empregar a técnica tendo todo aporte seguro e estável do espaço. Nas visitas técnicas, eles têm a oportunidade de buscar e alinhar a reflexão teórica e prática, e nas consultas de enfermagem, através da orientação e esclarecimentos, o discente vivencia novos conhecimentos e apresenta resolução diante dos problemas identificados nos clientes.

A Lei $n^{0}$ 7.498, de 25 de junho de 1986, prevê a consulta de enfermagem como atividade privativa do enfermeiro cabendo, portanto, às instituições de ensino introduzirem essa prática ainda no processo de formação dada sua relevância (BRASIL, 1986).

O consultório de enfermagem do Campus Taquara R9 é estruturado para atendimentos e consultas de diferentes ensinos clínicos práticos como os de saúde da mulher e saúde coletiva. Conta com equipamentos e insumos necessários ao desenvolvimento da prática e suporte de outros cursos, uma vez que a prática multidisciplinar também é foco dessa atividade. Para desenvolvimento das práticas de adulto e idoso, os discentes são inicialmente divididos em grupos de forma a otimizara atividade, garantir a privacidade do cliente e o desenvolvimento efetivo da proposta. As consultas acontecem mediante agendamento prévio realizado pela secretária e são conduzidas pelos discentes, do acolhimento às orientações, sem interferências ou interrupções pelo docente, salvo em situações específicas. O público-alvo são os moradores dos arredores do campus e também aqueles atendidos pela clínica de saúde existente na instituição.

A experiência mostrou que é possível desenvolver competências e habilidades no ensino clínico prático em adulto e idoso da graduação a partir das atividades práticas propostas pela disciplina. É possível trabalhar uma série de temáticas que permitem aos discentes solidificarem o conteúdo teórico-prático como estratégia de ensino-aprendizagem para o desenvolvimento dessas competências. A utilização da de tais ferramentas como instrumento de ensino baseado em metodologias ativas e problematização na graduação em 
enfermagem, possibilita ao docente a liberdade de atuação profissional, e aos discentes, no que tange à sistematização da assistência de enfermagem permite implementação efetiva desse processo. Cabe salientar que durante as práticasdesenvolvidas na disciplina, o discente apropria-se melhor de uma série de fatores inerentes ao processo trabalho do enfermeirocomo liderança, comunicação, interação, empatia, eregistros de enfermagem. Foi intrigante também identificar o quanto essas práticas, que fogem do método tradicional, os inquieta no sentido de fazer com que os mesmos aprendam a lidar tanto com essa liberdade, quanto com as tomadas de decisão na condução das atividades propostas e das consultas, os fazendo refletir o quão relevante deve sero papel e o protagonismo do enfermeiro.

\section{DISCUSSÃO}

\section{Metodologias ativas e o ensino}

As metodologias de ensino centradas no docente tendem a inibir oprotagonismo do discente e, consequentemente, minimizam os incentivospara o aprendizado do indivíduo. Logo, se o objetivo no processo de ensino-aprendizagem é propiciar sua autonomia e o desenvolvimento integral, o docente deve utilizar metodologias de ensino que busquem este fim (MOREIRA LM e LOPES TIB, 2019). A nova configuração dos perfis profissionais exige da educação e das políticas de saúde novas orientações pedagógicas que possam nortear a formação profissional.

Além da revisão dos conteúdos curriculares imbuídas nesse processo, faz-se necessário também considerar a perspectiva das metodologias de ensino-aprendizagem, que perpassam a orientação desse novo perfil profissional exigido pela sociedade, na qual se pretende formar (MENDES MG. et al. 2012).

A metodologia ativa no ensino em saúde dentro contexto interdisciplinar, nos cursos da área da saúde e na enfermagem apresenta-se diferente das outras metodologias de ensino à medida que promove a aprendizagem experiencial, a reflexão crítica, centrada no aluno e com apoio do docente em ambiente seguro (OLIVEIRA SN, et al, 2014).

Frente às demandas de um mercado de trabalho cada vez mais exigente, as Instituições de Ensino Superior (IES) têm sido estimuladas a refletir acerca das mudanças do processo da educação, e desafiadas a reconhecer seu papel social, entre os quais o de romper com os modelos de ensino tradicional, e formar profissionais de saúde com capazes de promover a dimensão essencial do cuidado ao cliente. Nesse contexto, pode-se compreender que as metodologias ativas se baseiam em mecanismos de desenvolver o processo de aprender, utilizando experiências reais ou simuladas, com o intuito de propiciar as condições de solucionar desafios advindos das atividades essenciais da prática social, em diferentes contextos (MOREIRA LM e LOPES TIB, 2019).

Sua utilização torna-se assim, uma alternativa viável para contemplar as dificuldades e necessidades encontradas na formaçãobaseada apenas na transmissão doconhecimento que, por sua vez, podemcaminhar para o desuso, e/ ou aquelas foradas exigências atuais (SOUZA CS, et al., 2014).

Dentre os diversos métodos associados à metodologia ativa, tem-se: situações (ou aprendizagem) baseadas em problemas ou problematização, avaliação por pares, gamificação, atividades lúdicas, simulação realística e uso das narrativas. Durante as atividades realizadas em laboratório, por exemplo, são empregadas situações problema através de um cenário simulado, onde os discentes precisam prestar assistência de enfermagem ao paciente. Nesse momento de interação entre eles, os docentes ficam na condição de facilitadores do processo. Ao final da atividade é realizado um debriefing, cuja proposta não é apontar erros e sim fazê-los refletir acerca do cenário exposto. A experiência mostra que os discentes trazem situações além das experimentadas no cenário, uma vez que associam àquilo que foi vivido extracampo nas visitas técnicas e consultas de enfermagem. Nesse momento enquanto facilitadores, o docente transforma as vivencias ou colocações negativas em positivas do discente à luz do embasamento cientifico. Assim, as metodologias ativas, através da problematização permitem ao indivíduo a possibilidade de pensar, refletir, criar, questionar e ressignificar suas descobertas incessantemente (CRUZ RAO, et al., 2017). 


\section{Competências, habilidades e problematização}

Aprendizagem Baseada em Problemas (ABP) ou problematização surgiu na década de 1960 no Canadá, onde foi aplicada inicialmente em escolas de medicina. Apesar da aplicação inicial na área médica, a ABP tem sido utilizada em várias outras áreas do conhecimento, como: administração, arquitetura, ciências da computação, ciências sociais, economia, enfermagem, engenharias e matemática. No Brasil, essa metodologia é aplicada regularmente em algumas instituições de ensino. Através desse método, a cooperação entre os discentes é potencializada através da interdependência (possibilidade de resolução em grupo), e o desafio de aprender ocorre individualmente (auto interesse em resolver o problema). Dessa forma, o uso da problematização enquanto metodologia ativa permite despertar no discente sua curiosidade, à medida que estes são inseridos na teorização e constroem novos elementos ainda não considerados nas aulas ou na própria perspectiva do docente (MOREIRA LM e LOPES TIB, 2019).

A educação problematizadora trabalha o desenvolvimento das competências e habilidades a partir da vivência de experiências significativas pelos discentes. Em contraponto aos processos de aprendizagem tradicionais, está apoiada na aprendizagem por descoberta, e os conteúdos buscam fazer com que o discente desenvolva competências e habilidades inerentes à sua futura prática profissional. A problematização mostra claramente o desvio do foco do docente para o discente, que assume a corresponsabilidade pelo seu aprendizado; a valorização do aprender a aprender e o desenvolvimento da autonomia individual e das habilidades de comunicação (SOUZA CS, et al., 2014).

Essa comunicação permite codificações simples, onde são utilizados canais visuais, táteis, auditivos ou gráficos; e composta onde os recursos são utilizados de forma simultânea. Ambas as formas buscam, de forma lúdica trazem reflexões aos discentes permitindo ao docente outras formas de educação diferentes da bancária (FREIRE P, 2011).

Frequentemente, situações problema são utilizadas na graduação. Estas ocorrem onde quando o discente vivencia a experiência de resolução de um problema de modo a desenvolver saberes, habilidades e competências, sendo as situações expostas aos discentes individualmente, porém, com a possibilidade de resolução em grupo (LEON LB e ONÓFRIO FQ, 2015).

A problematização fundamenta-se, portanto, no uso contextualizado de uma situação problema para o aprendizado autodirigido. Enquanto que nos métodos convencionais o objetivo é a transmissão do conhecimento centrada no docente, em conteúdos disciplinares, na problematização o aprendizado é centrado no discente, que deixa de ser um receptor passivo da informação para ser agente ativo por seu aprendizado. Logo, a função do docente é atuar como orientador ou facilitador na aprendizagem, nos quais sua interação é muito mais intensa do que em aulas puramente expositivas (BARBOSA EF e DG, 2013).

\section{CONSIDERAÇÕES FINAIS}

A experiência vivenciada pelos docentes acerca das atividades práticas desenvolvidas na disciplina de ensino clínico prático de adulto e idoso da graduação em enfermagem demonstrou que o desenvolvimento das competências e habilidades pelo discente está diretamente atreladoà associação atuação dos conteúdos teóricos com as práticas desenvolvidas pela disciplina. $\mathrm{O}$ uso das metodologias ativas permite ao docente a autonomia necessária ao desenvolvimento do processo de ensino-aprendizagem em conformidade com o Projeto Pedagógico do Curso de Enfermagem da UNESA Campus R9 Taquara.

Diante disso, reiteramos a importância de se fortalecer cada vez mais a utilização das metodologias ativas e problematização nos ensinos clínicos práticos da instituição, pois estes proporcionam um melhor desenvolvimento dos discentes na disciplina, bem com a possibilidade de formação de profissionais críticos, reflexivos e munidos da autonomia necessária no que tange a vida profissional do enfermeiro. $O$ aprimoramento das competências e habilidades desenvolvidas através das práticas na tríade laboratório, visitas técnicas, consultório promovem uma experiência exitosa na relação entre docentes e discentes, tornando-se ferramenta estimuladora que contribui diretamente na qualidade da formação do enfermeiro. 


\section{REFERÊNCIAS}

1. BARBOSA EF; MOURA DG. Metodologias ativas de aprendizagem na educação profissional e tecnológica. Boletim Técnico do Senac, Rio de Janeiro. 2013; v. 39, n. 2, p. 48-67, maio/agosto.

2. CARVALHO ACDO, et al. O planejar docente: uso de métodos ativos no ensino de Enfermagem. JournalofNursing UFPE. 2016; 10(4):1332-38.

3. CHAGAS N, et al. As metodologias ativas de ensino e aprendizagem na práxis interdisciplinar a partir do projeto versusoeste catarinense: o que as experiências dizem?Revista de Extensão da Universidade de Cruz Alta; 2018;10(1):190-204.

4. CONSELHO FEDERAL DE ENFERMAGEM (COFEN). Resolução COFEN no 358/2009, de 15 de outubro de 2009. Dispõe sobre a Sistematização da Assistência de Enfermagem e a implementação do Processo de Enfermagem em ambientes, públicos ou privados, em que ocorre o cuidado profissional de Enfermagem, e dá outras providências. In: Conselho Federal de Enfermagem [legislação na internet]. Brasília (DF); 2009.

5. CRUZ RAO, et al. Reflexões à luz da Teoria da Complexidade e a formação do enfermeiro. RevBrasEnferm. 2017; 70(1): 236-239.

6. EMILIANO MS, et al. A percepção da consulta de enfermagem por idosos e seus cuidadores. Revenferm UFPE online. Recife. 2017.11(5):1791-7.

7. FERREIRA NRS, et al. Prática docente interdisciplinar e aprendizagem midiatizada. Interdisciplinaridade / Grupo de Estudos e Pesquisa em Interdisciplinaridade (GEPI) - Educação: Currículo - Linha de Pesquisa: Interdisciplinaridade - n.8 (abr. 2016) - São Paulo: PUCSP, 2016.

8. FREIRE P. Pedagogia do oprimido. 50. ed. São Paulo: Paz e Terra, 2011.

9. GONZÁLEZ-CHORDÁ VM; MACIÁ-SOLER ML. Avaliação da qualidade do processo ensino-aprendizagem no curso de graduação em Enfermagem. RevLatAm Enfermagem.2015; 23(4): 700-707, July-Aug.

10. HUMEREZ DC; JANKEVICIUS JV. Reflexão sobre a formação das categorias profissionais de saúde de nível superior pós diretrizes curriculares. Brasília, DF: Cofen, 2015.

11. LEON LB; ONÓFRIO FQ. Aprendizagem baseada em problemas na graduação médica: Uma revisão da literatura atual. Revista Brasileira de Educação Médica, Rio de Janeiro. 2015; v. 39, n. 4, outubro/novembro.

12. MENDES MG. et al. Contributos da aprendizagem baseada em problemas no desempenho do estudante de enfermagem em ensino clínico. Revista de Formación e Innovación Educativa Universitaria. 2012;5(4):227-40.

13. Ministério da Educação (Brasil). Conselho Nacional de Educação, Câmara de Educação Superior. Resolução CNE/CES n. 3, de 07 de novembro de 2001. Institui as Diretrizes Curriculares Nacionais do Curso de Graduação em Enfermagem. Diário Oficial da República Federativa da União. Brasília, 09 nov. 2001. Seção 1, p. 37. Brasília (DF): Ministério da Educação e Cultura, 2001.

14. Ministério da Saúde (Brasil). Lei 7.498, de 25 de junho de 1986. Dispõe sobre a Regulamentação do Exercício da Enfermagem e dá outras providências. Diário Oficial da República Federativa da União. Brasília, 26 jun. 1986. Seção 1, p. 9273.Brasília (DF): Ministério da Saúde; 1986.

15. MOREIRA LM; LOPES TIB. Aprendizagem baseada em problemas (ABP):proposta de modelo pedagógico e avaliação da efetividade na educação profissional. Revista Brasileira da Educação Profissional e Tecnológica, 2019;[S.I.], v.1, n.16, p. e7963, jun.

16. OLIVEIRA SN, et al. Utilização da simulação no ensino da enfermagem: revisão integrativa. REME Ver Min Enferm [serial on the internet]. 2014; 18(2):487-95.

17. Projeto Pedagógico de Curso (PPC):Graduação em Enfermagem - Campus R9 Taquara, Universidade Estácio de Sá (UNESA). Rio de Janeiro, 2019.

18. RAULI, PMF et.al. Bioética e metodologias ativas do ensino - aprendizagem. Volume 7. Curitiba: CRV, 2018. Pag. 64.

19. ROSA RS, et al. Estratégias baseadas em metodologias ativas no ensino-aprendizagem de primeiros socorros: relato de experiência. Revenferm UFPE online, Recife. 2017; 11(2):798-803, fev.

20. SILVA KLD, et al. Entre experimentações e experiências: desafios para o ensino das competências para a promoção da saúde na formação do enfermeiro. Interface-Comunicação, Saúde, Educação, 2018; 22(67): 1209-1220.

21. SOUZA EFDD, et al. Metodologias ativas na graduação em enfermagem: um enfoque na atenção ao idoso. RevBrasEnferm, 2018; 71(supl.2): 920-924.

22. SOUZA CS, et al. Estratégias inovadoras para métodos de ensino tradicionais: aspectos gerais. Medicina (Ribeirão Preto). 2014;47(3): 284-92. 